\title{
Seasonal grouping dynamics in a territorial vulture: ecological drivers and social consequences
}

\author{
Thijs van Overveld $^{1}$ (D) $\cdot$ Laura Gangoso ${ }^{2}$ - Marina García-Alfonso ${ }^{1} \cdot$ Willem Bouten ${ }^{2} \cdot$ Manuel de la Riva $^{1}$. \\ José Antonio Donázar ${ }^{1}$
}

Received: 14 August 2019 / Revised: 9 January 2020 / Accepted: 17 January 2020 / Published online: 27 January 2020

(C) Springer-Verlag GmbH Germany, part of Springer Nature 2020

\begin{abstract}
Despite widespread occurrence of seasonal sociality among animals, little is still known about the social drivers and populationlevel social implications of seasonal grouping behaviours, especially in birds. Here, we studied the combined effects of ecological and social factors on seasonal grouping patterns in a sedentary population of Egyptian vultures living on the Eastern Canary Islands. We focussed on the social significance of large-scale gatherings taking place outside the breeding season at a highly preferred feeding station and a nearby temporary roost. Group sizes at this feeding patch followed a strong seasonal pattern characterized by distinct monthly changes in group composition, according to sex, age and territorial status. In between reproductive periods, vulture numbers at the feeding station may reach up 50\% of the total population on a single day. GPS-tracking showed that this increase in vulture numbers was in part due to a shift in foraging range towards the centre of Fuerteventura by low-ranked territorial birds breeding in remote areas. During this period, vultures may spend on average $30 \%$ of their monthly time in a social gatherings context, depending on social status. We show that seasonal grouping patterns are shaped by the complex interplay between ecological factors (reproductive constraints, resource seasonality, food predictability), age-specific traits and social competitive processes, while social attraction may be an important additional component. We propose that for facultative social foragers living in highly despotic territorial systems, collective foraging may be of particular relevance regarding the development of hierarchical social relations and maintenance of population-level social cohesion.
\end{abstract}

\section{Significance statement}

We show that seasonal grouping patterns in a sedentary island population of a territorial vulture are shaped by the complex interplay between ecological factors (reproductive constraints, resource seasonality, food predictability), age-specific traits and social competitive processes. We argue that vultures visit large gatherings also for social purposes. Group foraging events may be of special interest to vultures, given opportunities for rank maintenance/improvement, but also for conspecific evaluation and mate-seeking, and play an important role in the social structuring of populations. Vultures may serve as important model species to test the role of scavenging and fission-fusion social dynamics in driving the evolution of avian social cognition, or avian social complexity in general.

Keywords Egyptian vultures $\cdot$ Feeding stations $\cdot$ Social interactions $\cdot$ Seasonal sociality $\cdot$ Social complexity

Communicated by C. R. Brown

Electronic supplementary material The online version of this article (https://doi.org/10.1007/s00265-020-2807-4) contains supplementary material, which is available to authorized users.

Thijs van Overveld mathijs.van.overveld@gmail.com

1 Department of Conservation Biology, Estación Biológica de Doñana (CSIC), Américo Vespucio 26, 41092 Sevilla, Spain

2 Theoretical and Computational Ecology, IBED, University of Amsterdam, Science Park 904, 1098

XH Amsterdam, The Netherlands

\section{Introduction}

Seasonal changes in social behaviour are widespread among animals and often linked to cyclic variation in food availability and phenology (e.g. reproduction) (Sueur et al. 2011; Silk et al. 2014). A prominent example of this is found in the formation of large aggregations around scarce and patchily distributed food resources during the non-breeding season (Krause and Ruxton 2002; Møller and Laursen 2019). While the role of ecological factors in shaping seasonal groupings is well-established, still, little is known about the extent to which 
social factors also contribute (Sueur et al. 2011; Silk et al. 2014). However, it is increasingly recognized that many birds and mammals live in social systems that are structured by long-term affiliative and agonistic relations (Massen 2018; Kappeler 2019). Recent work suggests that seasonal aggregations may fulfil a crucial role in the development and maintenance of social relationships (Fishlock and Lee 2013; SmithAguilar et al. 2016; Uhl et al. 2018) and importantly contribute to the social structuring of populations (Aureli et al. 2008; Sueur et al. 2011; Boucherie et al. 2019). To date, however, detailed studies investigating the combined effects of ecological and social factors underlying seasonal aggregations are still scarce, hampering a more comprehensive understanding of the social significance of this phenomenon.

While considerable attention has been given to the structure and dynamics of mammalian social groupings (Kappeler et al. 2019), information about the relative complexity of avian social systems is still limited and largely restricted to research performed on corvids (Boucherie et al. 2019). Members of this family are renowned for their sociality and welldeveloped socio-cognitive skills (Emery and Clayton 2004; Emery et al. 2007). Most species live in social systems that are structured by clear dominance relations, often consisting of social alliances among young subdominant birds (Dall and Wright 2009; Boucherie et al. 2016). They maintain their strong social relations by providing each other social support (Fraser and Bugnyar 2012), by complex forms of conflict management (Fraser and Bugnyar 2011) and through sophisticated ways of social reasoning, allowing a fine-scaled assessment of the dominance rank of conspecifics as well as their own social position within groups (e.g. Paz-y-Miño et al. 2004; Massen et al. 2014). Their habit of living in 'open groups' (Richner 1989; Marzluff and Heinrich 1991), characterized by high degrees of fission-fusion dynamics (Aureli et al. 2008), is assumed to be a key driving force behind the evolution of corvid cognition and social complexity (Boucherie et al. 2019). Especially outside the breeding season, the composition of these groupings may be socially complex, consisting of a mixture of new visitors (i.e. dispersers, fledglings) and breeders that meet again after a period of reproduction (Loretto et al. 2017; Uhl et al. 2018). Repeated interactions with conspecifics at these groupings may promote the development of new social relationships but also select for enhanced cognitive skills needed to reorganize social structures and/or to re-establish existing relationships (RamosFernandez et al. 2018; Boucherie et al. 2019). So far, however, little is known about levels of social complexity in other groups of bird displaying similar forms of fission-fusion sociality.

A group of species that show strong parallels in socioecology with corvids are vultures. Both groups of species are scavengers, with vultures being obligate carrion consumers that rely almost exclusively on ephemeral, unpredictable food resources (Campbell 2015). Like corvids, vultures are well known for their complex grouping dynamics. Although foraging often occurs solitarily, or in small, highly dispersed groups, individuals frequently merge to form large gatherings around carcasses, communal roosts or resting areas (Campbell 2015). Vultures show a marked diversity in breeding systems, ranging from strict territoriality to various forms of social breeding, characterized by distinct speciesdifferences in group foraging, hierarchical social structures and mating behaviours (reviewed in $\mathrm{TvO}$ et al. unpublished data). Although vulture grouping dynamics have been extensively studied from a social foraging perspective (e.g. Buckley 1997; Dermody et al. 2011; Cortés-Avizanda et al. 2014; Harel et al. 2017), other aspects of their social living remain largely unexplored. In fact, despite the highly threatened status of many vulture species (Ogada et al. 2012; Buechley and Sekercioglua 2016), their behavioural and socio-ecology still remains among the least understood of birds.

The Canarian Egyptian vulture (Neophron percnopterus majorensis), living on the Eastern Canary islands (Fuerteventura and Lanzarote), provides an excellent model species to study vulture social dynamics and complexity. They are long-lived and highly social birds that aggregate when feeding and roosting but display high levels of territoriality during the breeding season. Insular populations of Egyptian vultures are sedentary (Donázar et al. 2002a; Porter and Suleiman 2012), probably resulting in a higher frequency of repeated interactions among individuals and more intense social conditions compared to migratory mainland populations. In previous work, we showed that their social system is characterized by strong female-dominance social structures, with non-territorial and young individuals of both sexes having a lower social position that increases with age (van Overveld et al. 2018). Dominant females rely more on predictable food provided at a feeding station located in the centre of Fuerteventura, and breed closer to this site, while subdominant females and dominant males rely more on farms as their main source of food. However, outside the breeding season, individuals form large gatherings at this specific feeding patch, which is visited by both low- and high-ranked individuals, despite the presence of other feeding stations on both islands (van Overveld et al. 2018). In the same period, vultures also form a large temporary roost located at ca $5 \mathrm{~km}$ distance from the central feeding station.

Here, by combining different sources of data (visual observations of individually marked vultures, GPS-tracking and behavioural observations), we assess the different ecological and social drivers underlying their seasonal grouping patterns. Our main aims were twofold: (1) to quantify different aspects of seasonal social dynamics, in particular temporal variation in group size and structure (i.e. the number and composition of vultures visiting the feeding station) and temporal variation in socializing activities (i.e. time-activity patterns at both the 
feeding station and mountain roost) and (2) to extend previous findings on the interplay between ecological factors (breeding activities), individual traits (sex, age, territorial status, social rank) and social competition underlying seasonal changes in grouping habits.

Our predictions were as follows: First, we hypothesise that seasonal variation in vulture numbers at the feeding station is associated with distinct seasonal changes in group compositions. In particular, we predict a decrease in the number of adult breeders during the breeding season, but also in the number of unpaired birds because of information gathering on adult breeding activities (van Overveld et al. 2018). However, we expect the number of young birds (immatures) to remain relatively constant throughout the year given their poor foraging skills. By contrast, we predict non-breeding gatherings to be visited by the majority of vultures within the population (including most recently fledged juveniles and vultures from the nearby island of Lanzarote), despite increased levels of competition for food and the availability of carcasses at other feeding sites. Second, we hypothesise that seasonal changes in activity patterns at the feeding station (i.e. vulture numbers and time spent at this site) are part of an overall shift of vulture activities towards the centre of Fuerteventura (i.e. reflecting broad-scale seasonal fissionfusion dynamics at the population-level). We expect that adult breeders increasingly abandon their territory during the nonbreeding season, but that territorial structures remain intact throughout the year, given the high value of this resource, especially for high-ranked breeders. In addition, we expect the mountain roost to fulfil a specific role as a gathering place for unpaired birds and low-ranked breeders that are less attached to territories. Lastly, we provide descriptive information about antagonistic (ritualized dominance displays, escalated fights) and affiliative behaviours (non-reciprocal allopreening) displayed at the feeding station, to show that vulture gatherings are more than simple aggregations at food resources.

\section{Methods}

\section{Study population}

The endemic Canarian subspecies of Egyptian vulture was once abundant throughout the Canarian archipelago, but its range is currently restricted to the eastern islands (between $27.62^{\circ}-29.42^{\circ} \mathrm{N}$ and $13.33^{\circ}-18.17^{\circ} \mathrm{W}$ ) (Donázar et al. 2002a). The species almost went extinct during the second half of the twentieth century with only 20 occupied territories present on Fuerteventura and Lanzarote in the mid-nineties (Donázar et al. 2002b). Extensive research and the application of several protection measures have resulted in a current estimated population size of ca. 350 birds in 2018 (TvO et al. unpublished data). Fuerteventura $\left(1662 \mathrm{~km}^{2}\right)$ is the stronghold of the population ( 68 breeding pairs in 2018), while Lanzarote $(845.9 \mathrm{~km} 2)$ and adjacent islets are home to six breeding pairs. Yearly ringing of fledglings and trapping of adults (through cannon-netting) has resulted in over $90 \%$ of the total population being marked allowing individual identification in the field.

As part of the species' recovery plan, three feeding stations were created on the islands and are maintained all year-round by local administrations. One feeding station is located in the centre and one in the north of Fuerteventura (created in 1999 and 2008 respectively, and separated by approximately $40 \mathrm{~km}$ distance) and one on the East coast of Lanzarote (created in 2016, distance ca. 60 and $100 \mathrm{~km}$ from the other two feeding stations; Fig. 1). Although each of the three feeding stations is provided with goat and sheep carcasses by local farmers, the central feeding station is also provisioned with slaughterhouse remains $( \pm 200 \mathrm{~kg}$ per week consisting of pig heads and viscera). In the past, slaughterhouse remains were also provided at the northern feeding station, but this was stopped because few birds visited this site (JAD and MdlR, pers. obs.).

Vultures may use small roosting sites (fewer than five birds) throughout the islands but concentrate in four large communal roosting areas throughout the year (usually with more than 30 birds) all on electricity pylons located near sites with a predictable food supply. They also gather at two sites located in the mountains in the centre of the island at respectively 5 and $8 \mathrm{~km}$ distance from the central feeding station (Fig. 1; Fig. S1, distance between sites $6 \mathrm{~km}$ ). Note that these sites are used both as a diurnal and nocturnal roost.

\section{Seasonal dynamics of social gatherings}

To quantify seasonal variation in gatherings at the central feeding station, we used data on visual observation of ringed birds from a hide (using telescopes) between February and September 2016. We included only observations made on the first day of fresh food supply. We focussed on this specific year because we performed additional extensive observations on agonistic interactions ( $>500 \mathrm{~h}$, see below), in addition to the standard monitoring work. This period covers the entire reproductive season (March-June), the months when the temporary roost is formed (August-September) and the prebreeding period (February) during which many pairing activities can be observed. We calculated the proportion of adult unpaired and paired birds, immatures and juveniles (newly fledged birds) visiting this feeding station relative to the total population composition, the latter being quantified by using all available visual observations of ringed birds collected throughout the year at feeding stations, roost-sites and breeding territories (see Table 1 for details).

We used GPS-tracking data of 45 birds (UvA-BITS www. uva-bits.nl, The Netherlands, $n=26$ and e-obs Digital 


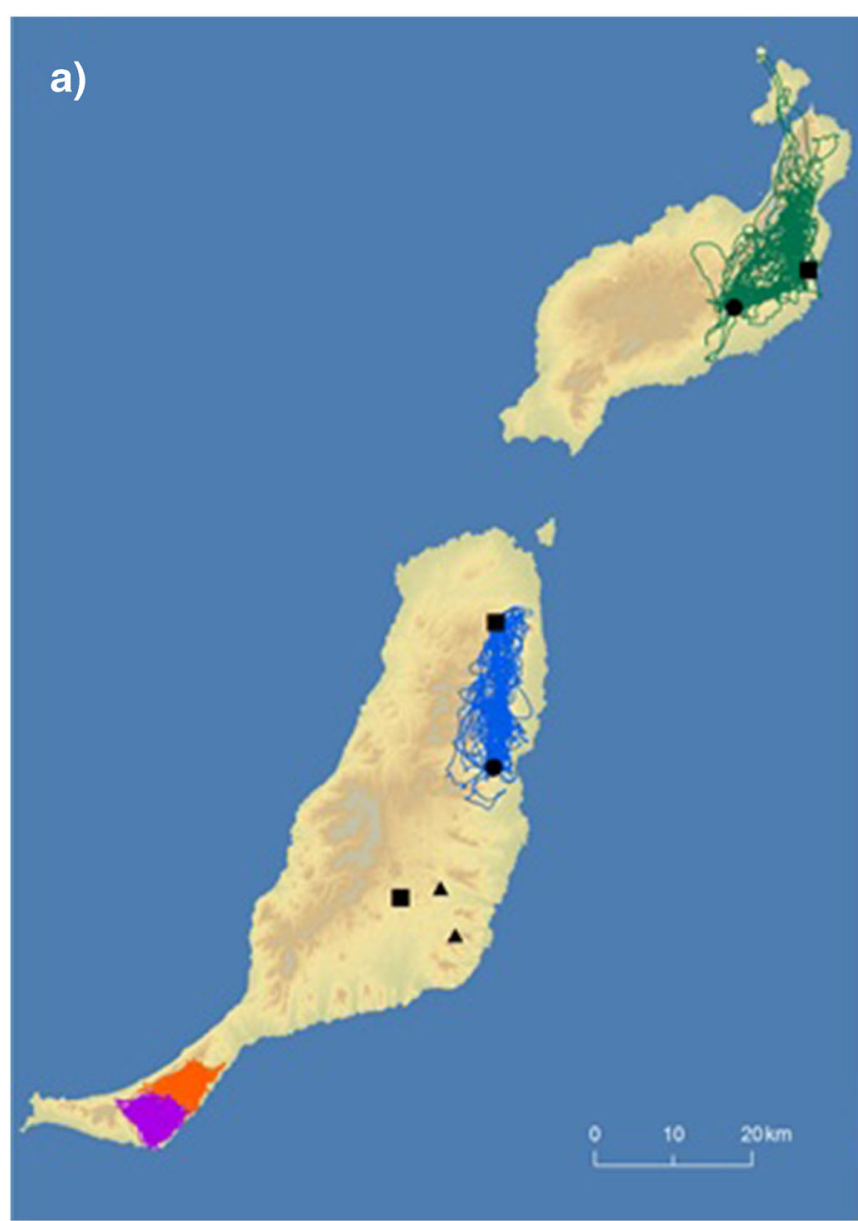

Fig. 1 Overview of the study area, Lanzarote (top) and Fuerteventura (bottom) and the location of the feeding stations (squares), garbage dumps (dots) and temporary mountain roost (triangles). The movements of four territorial females in May 2016 (chick-rearing period, panel a) and September 2016 (social gathering period, panel b) are shown (same

Table 1 Overview of the population structure and age-composition of birds marked with PVC-rings $(n=277)$ and GPS-trackers $(n=42)$ in 2016

\begin{tabular}{lllllll}
\hline & PVC & Age & & GPS \\
Category & $N$ & Median & $\begin{array}{l}\text { Age } \\
\text { Median }\end{array}$ & Range \\
\hline Paired & & & & & & \\
$\quad$ Males & 44 & 10 & $5-22$ & 9 & 6 & $5-10$ \\
$\quad$ Females & 56 & 10.5 & $4-20$ & 13 & 9.5 & $5-13$ \\
Unpaired & & & & & & \\
Males & 45 & 4 & $3-16$ & 10 & 5 & $3-7$ \\
Females & 33 & 6 & $3-19$ & 10 & 6.5 & $3-7$ \\
Immatures & & & & & & \\
Males & 39 & 2 & $1-2$ & & & \\
Females & 21 & 2 & $1-2$ & & & \\
Juveniles & & & & & & \\
Males & 21 & 0 & & & & \\
Females & 18 & 0 & & & & \\
\hline
\end{tabular}

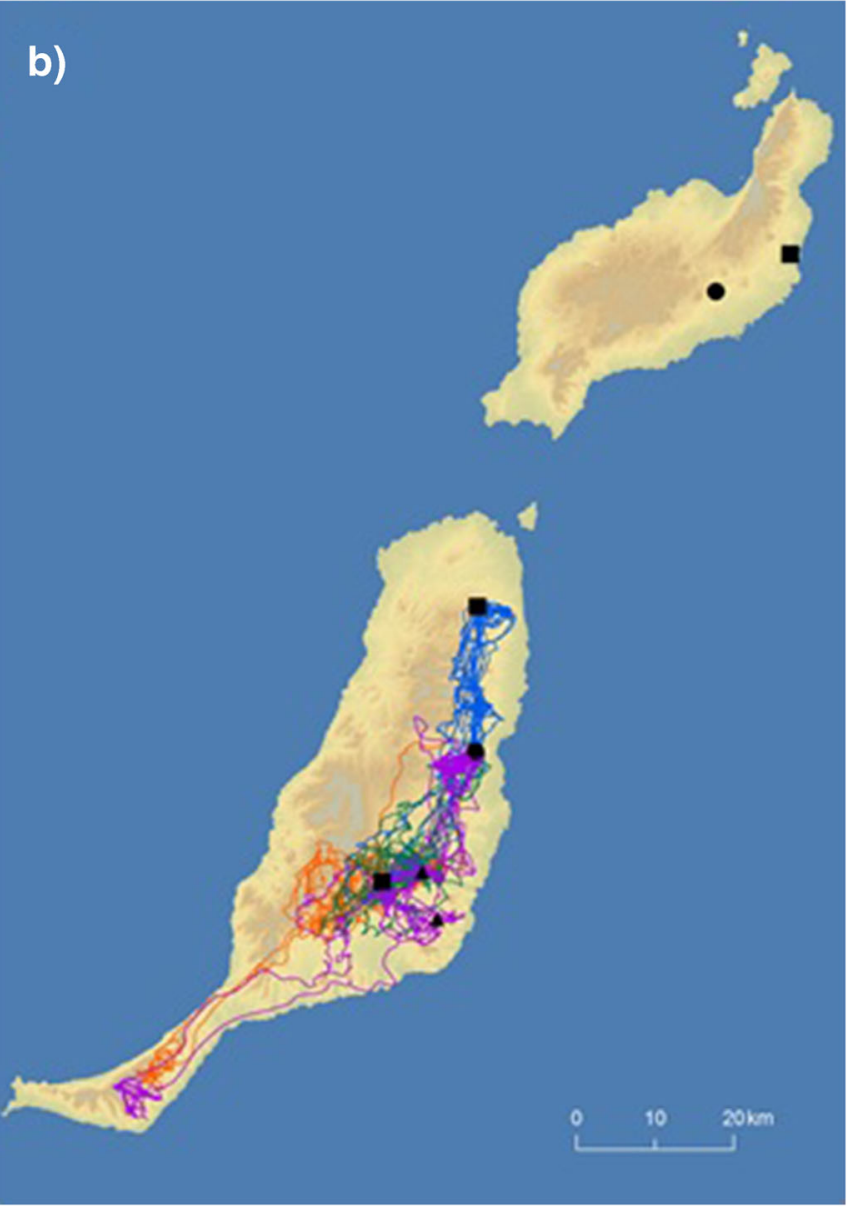

colour lines correspond to the same individual). Note the shift in foraging range towards the centre of Fuerteventura associated with the abandonment of territories. Also note the clear preference to forage at the centrally located feeding station, despite the presence of other supplementary feeding patches

Telemetry, Grünwald, Germany, $n=19)$ tagged between October 2015 andDecember 2017 to assess between-year consistency in patterns of gathering at both the feeding station and resting area. Sample size slightly differed between study years: $2015, n=43$; 2016, $n=45 ; 2017, n=42$, and some trackers were re-used in case individuals died. GPS-tags were attached to the bird using backpack harnesses. The total weight of the system varied between $31 \mathrm{~g}$ (UvA-BiTS) and $54 \mathrm{~g}$ (e-obs), representing 1.4-2.4\% of the bird body mass, which is well below the percentage assumed to be harmless to the individual (Sergio et al. 2015) .

Given the difficulty in observing vulture numbers and identities at the mountain resting sites, we could only use GPStracking data to quantify seasonal variation in vulture numbers. An estimate of actual vulture numbers was made by extrapolation of the relationship between vulture numbers and GPS-tracked birds at the central feeding station. Note that these extrapolated numbers represent a rough estimate since the relationship between GPS-tagged birds and total vulture numbers at both sites is unclear. 


\section{Monthly activity budgets}

To construct monthly activity budgets, we used GPS-fixes between sunrise and sunset, excluding data from night-time, and distinguished between time allocated to flight vs. non-flight behaviour (including resting and foraging) using a threshold ground speed $3 \mathrm{~m} \mathrm{~s}^{-1}$ (following similar procedures as in van Overveld et al. 2018). We used data from paired and non-paired males and females tracked over a 12-month period between June 2016 and May 2017 (details in Table 1). GPS-loggers were programmed to record locations every 1 to $5 \mathrm{~min}$, but data were re-sampled to a resolution of $10 \mathrm{~min}$ (range 9-11 $\mathrm{min}$, Rfunction developed by D.S. Viana, see Suppl. Mat.) to allow direct comparison between individuals and both GPS devices. GPS locations with intervals exceeding this 10-min resolution (i.e. owing to battery and/or satellite reception issues) were removed from the dataset. Year-round, non-flight behaviour was further subdivided into time allocated at the mountain roosts (daytime only, see above), feeding stations and the nest location by using the number of GPS locations within a buffer zone of $300 \mathrm{~m}, 75 \mathrm{~m}$ and $1 \mathrm{~km}$ around the centre of each place, respectively. Note that in the latter case, behaviour may not include only resting but also feeding at natural available carrion resources. We excluded time spent at the territory and mountain roost of one female with a territory in close proximity to the mountain roost $(<50 \mathrm{~m})$.

\section{Social interactions at the central feeding station}

Data on social dominance were collected in February 2016 (pre-breeding season) and August-September 2016 (postbreeding season). We recorded all agonistic displacements between ringed individuals around baits between sunrise and sunset. In total, we observed 4593 interactions between 141 individuals being involved in more than 20 displacements (average 65.1 $\pm 3.0 \mathrm{SE}$, range 20-175). Rank scores for each individual were determined using David's score corrected for chance of encounter and thus independent of group size or visiting rate (Gammell et al. 2003) using the ds.R function within the 'compete' package (Curley 2016) for R software (R Core Team 2017). Rank was scaled between 0 and 1 with 1 being the most dominant bird. Rank order relationships according to sex, age and territorial status are presented in Fig. S2.

In addition, we provide descriptive information on agonistic and affiliative behavioural displays. Although we quantified social competitive interactions according to intensity on a scale between 1 and 3 ( $1=$ push/non-contact displacement, $2=$ peck or kick and $3=$ more elaborate physical contact), most $(90 \%)$ of interactions were scored as $1 \mathrm{~s}$ or $2 \mathrm{~s}$. Although during initial crowd-foraging for food (in case of viscera) interactions can be slightly more intense and difficult to assess, overall levels of aggression during food exploitation (pig heads/goat carcasses) are typically low. Therefore, we provide video examples of their ritualized dominance displays and rare occasion of escalated fights (see discussion) which we consider highly illustrative and informative for understanding low levels of aggression and their hierarchical way of living. We also provide information about allopreening behaviours displayed outside a pair-living context between individuals of known sex, age and, in most cases, degree of kinship. Note that these observations are not an indication of the frequency of the behaviour, as it was not the main focus of behavioural observations. Also, we only include information of the behaviour in case where we were able to read the ring of at least one individual. It was not possible to record data blind because our study involved focal animals in the field.

\section{Data analyses}

Patterns of activity of GPS-tagged birds were analysed using SAS 9.4 software (SAS Institute Inc., Cary, NC). First, we assessed whether seasonal time-activity patterns at the central feeding station (June 2016 to May 2017) differed between individual categories using a linear mixed model (LMM). We included sex, territorial status, social rank and month as fixed terms plus all interactions. Since seasonal time-activity patterns varied in a non-linear manner, we included month ${ }^{2}$ and a four-way interaction term $\left(\right.$ month $^{2} \times \operatorname{sex} \times$ territorial status $\times$ social rank) to test for trait-specific differences in seasonal time activities. Second, we assessed whether time spent at mountain resting area (September/October 2016) differed between categories, using a similar model, but without testing for seasonal effects. Lastly, we assessed whether time activities differed between sites, using a similar model, but including a categorical variable 'site' (feeding station or mountain resting area) as a fixed term. We also tested whether birds that did not visit the mountain resting area $(n=12)$ also spent less time at the feeding station, by including a categorical variable 'presence' (yes or no). We performed additional analyses on territorial birds to test for dominance-specific seasonal changes in time spent at territories (June 2016-May 2017). We fitted separate models for males and females and included month ${ }^{2}$ and a two-way interaction (month ${ }^{2} \times$ dominance rank) in both models. Note that month was included as a continuous variable in models on time spent at the feeding station and territories, but as a categorical variable in models on time spent at the mountain resting area. All dependent variables (percentage of monthly time) were square-root transformed to attain normality of residuals. Bird ID was included as a random term in all models.

\section{Data availability}

The datasets generated and/or analysed during the current study are available in the [Figshare] repository, [Egyptian 
vultures seasonal sociality: https://doi.org/10.6084/m9. figshare.11339807].

\section{Results}

\section{Social gatherings at the central feeding station}

GPS-tracking revealed a clear seasonal pattern in the number of individuals visiting the central feeding station (Fig. 2), with lowest numbers during the breeding season (Jan-Jun) and highest numbers outside this period (Jul-Dec). Data on visual observations confirmed this pattern, showing an increase in vulture numbers towards the end of the breeding season, with a peak in September, when approximately half of the total population visited this feeding patch on days of fresh food supply (Fig. S3). Vulture numbers also showed a clear daily pattern, with large numbers of feeding birds in the morning, and an increase in resting vultures in the afternoon, reaching up to 65 birds in September (Fig. S4). The highest proportion of unpaired males and females (relative to the total population of unpaired birds) was reached in February ( $82 \%$ and $67 \%$, respectively) and August/September (73\% and 63\%, respectively) (Fig. S5; see also Fig. S6 for an example of large-scale explorative flights made by males during the breeding season). The proportion of paired birds increased from March onwards reaching maximum numbers in September $(>65 \%$ in both sexes; Fig. S5). The number of immature birds was relatively consistent throughout the year (ca. $60 \%$ of both sexes; Fig. S5), but also increased after the breeding season (> 80\%). A sharp drop in the number of female immatures occurred in June-July. The total number of birds observed

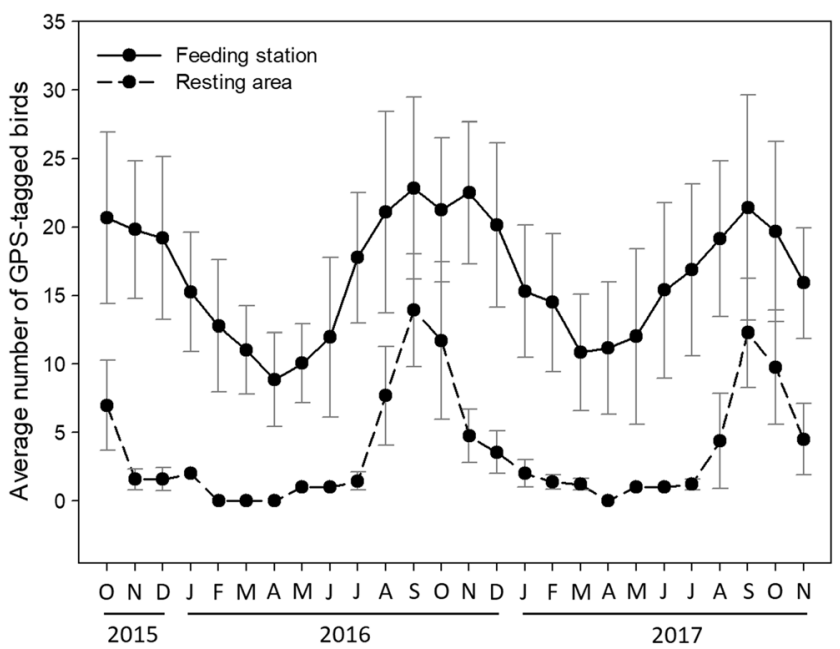

Fig. 2 Average monthly variation (error bars represent the standard deviation) in GPS-tagged birds visiting the feeding station (solid line) and mountain resting area (dashed line) between October 2015 and November 2017. Data based on 45 GPS-tagged birds $(2015, n=43$; $2016, n=45 ; 2017, n=42$ ) between 11 Aug 2016 and 29 Sep 2016 was 204 (ca.74\% of the total population), which included five birds (out of five pairs) with a territory on Lanzarote (two females and three males, see also Fig. 1; see Fig. S2 for an example of the movements of a breeding female from Lanzarote to the centre of Fuerteventura). Nearly all newly fledged juveniles were observed at this site (92\%), including all three juveniles fledged at Lanzarote. By contrast, vulture numbers recorded at the feeding station in the North (17 observation days between February-July) ranged between 2 and 23 individuals, consisting of four males and five adult females (territory distance $<20 \mathrm{~km}$ from this site, but including one male from Lanzarote), 38 and 16 unpaired males and females respectively and five and two immature males and females respectively.

\section{Social gatherings at the mountain resting area}

The existence of a mountain roost was first observed in early fall 2002, when 35 individuals of different age classes were recorded resting on a mountain cliff (corresponding to ca. $30 \%$ of the population at that time). A new mountain roost was located in autumn 2003 at $6 \mathrm{~km}$ from the feeding station, which has become their preferred roosting site in the last 5 years. GPS data revealed that vultures typically form gatherings at this site outside the breeding season, showing a peak around Sep-Oct in all years (Figs. 2 and 3). The number of different GPS birds visiting the resting area in these months was 27/27 in 2016 and 27/30 in 2017 (>60\% of total tagged birds). Extrapolating from the relationships between number of visually observed birds and GPS-tagged birds at the central feeding station (Pearson correlation, $\mathrm{r}=0.84, p<0.001, n=$ 69 , equation: $y=3.95 x-3.08)$, the estimated daily number of birds at the resting area in September/October in 2016 was ca. 35 (range 1-80) and ca. 31 (range 1-75) in 2017. Irregular visits at this site at the end of August in 2018 seem to confirm these numbers (ranging between 24 and 44, mostly adults; TvO, pers. obs.). Although the occurrence of this resting area overlaps with temporal increases in numbers at the central feeding station, the daily numbers of GPS birds at both sites were not correlated ( $\mathrm{r}=-0.11, p=0.24, n=115$ days).

\section{Time-activity patterns at the mountain resting area, feeding station and territories}

The average monthly percentage of time spent at the mountain resting area (during daytime) and feeding station in September/October 2016 (pooled) was $14.6 \% \pm 10.0 \mathrm{SD}$ and $13.9 \% \pm 10.8 \mathrm{SD}$, respectively (details in Table 2). During this period, the majority of territorial birds also spent a considerable amount of time within $<1 \mathrm{~km}$ of their nest (average percentage of monthly time $12.9 \% \pm 12.4 \mathrm{SD}$; details in Table 2, see also Fig. 3). 


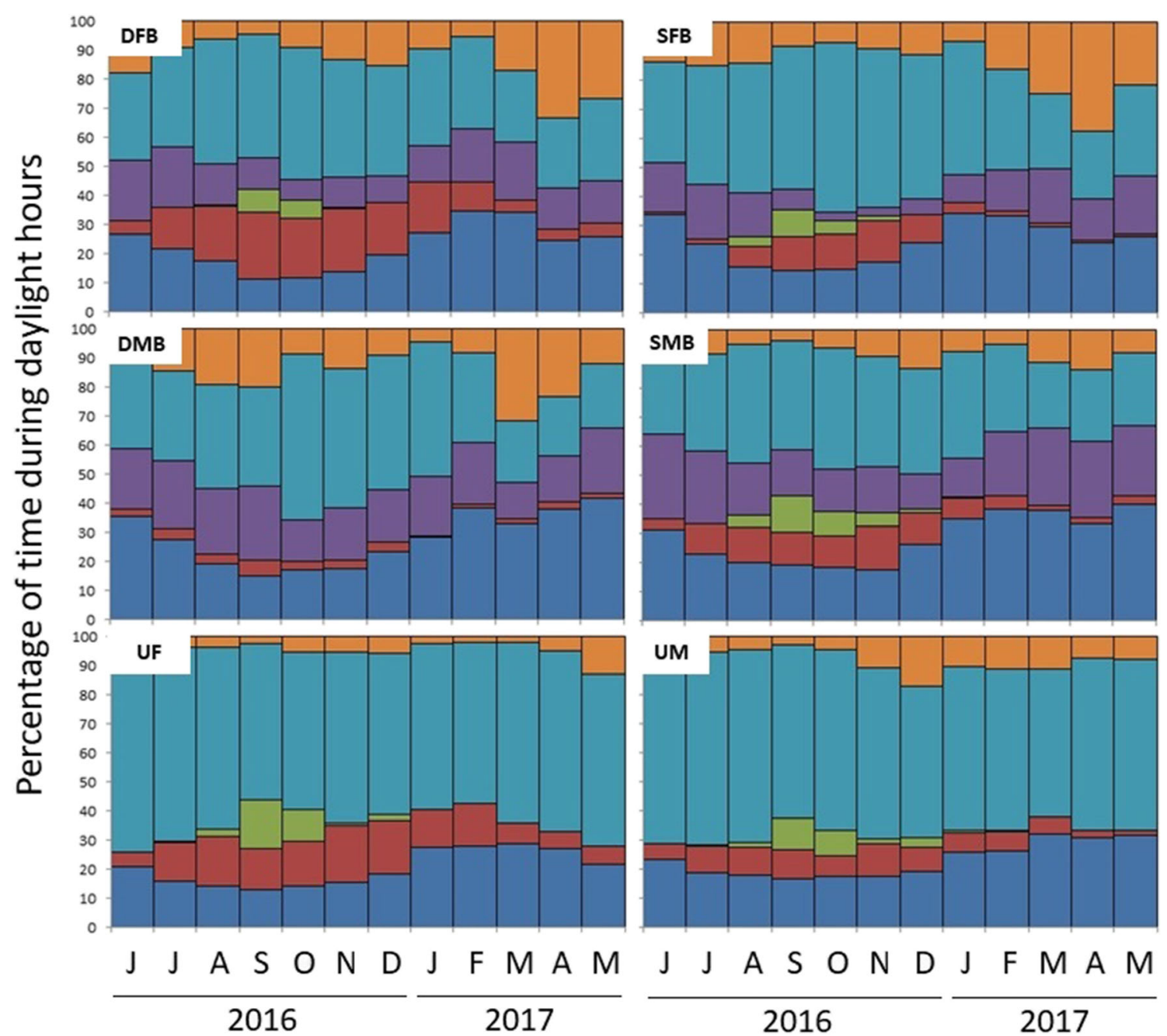

Fig. 3 Average monthly time-budgets of GPS-tagged Egyptian vultures $(n=42)$ on Fuerteventura between June 2016 and May 2017. Individuals were categorized according to breeding status and social rank (BFB dominant female breeders, $n=7)$, SFB subdominant female breeders $(n=5)$, DMB dominant male breeders $(n=4)$, SMB subdominant male breeders $(n=5)$, UF unpaired females $(n=10)$, UM unpaired males $(n=10)$.

Monthly time activities were quantified by time spent at the feeding station (red), mountain roost (green) and territories (purple). The remaining time was categorized as flight (dark blue), non-flight (light blue) and unexplained (i.e. no signal, orange). The high percentage of time without signal between March and May is due to birds incubating eggs on nest in caves or on cliffs with bad reception

Seasonal time-activity patterns at the feeding station differed strongly among individual categories and in relation to social rank (month ${ }^{2} \times$ sex $\times$ territorial status $\times$ social rank, $\mathrm{F}_{4,417}=4.66, p=0.0011$; Fig. 3). Further analyses revealed that within non-territorial males and females, there was no correlation between social rank and time activities at the central feeding station $(p>0.3)$, nor were there significant sexdifferences in time spent at this site $(p>0.1)$. However, in breeding adults, dominant females spent more time at the central feeding station throughout the year $(p=0.0273$; Table 3; Fig. 3), while no main effect of social status was found in males ( $p=0.89$; Table 3; Fig. 3). Outside the breeding season, subdominant territorial birds of both sexes increased the time spent at the central feeding station $\left(\right.$ rank $\times$ month $^{2}$; females: $\beta=-0.03 \pm 0.01, p=0.0061$; males: $\beta=-0.07 \pm 0.02$, $p<0.0001$; Table 1), while an opposite pattern was found

for time spent at territories (rank $\times$ month $^{2}$; females: $\beta=$ $0.04 \pm 0.01, p=0.0038$; males: $\beta=0.06 \pm 0.02, p<0.0108$; Table 3; see also Figs. 1 and 3).

There were no significant differences in time spent at the mountain resting area between territorial and non-territorial males and females (sex: $\mathrm{F}_{1,37}=0.41, p=0.52$; territorial status: $\mathrm{F}_{1,37}=2.92, p=0.10$, interactions: $p>0.29$ for all). However, non-territorial birds spent more time at the mountain resting area compared to the feeding station (territorial status $\times$ site: $\mathrm{F}_{1,114}=14.99, p=0.0002$; a similar but nonsignificant trend was found for birds visiting both sites: $\mathrm{F}_{1,66}=3.52, p=0.0652$ ). For territorial birds, no effect was detected of distance between the nest-site and mountain resting area on the time spent at this site $(p>0.8)$. There were six females and six males (consisting of four territorial and two non-territorial birds in each sex) that did not visit the resting 
Table 2 Summary of time spent at the mountain resting area and feeding station for territorial and non-territorial birds and time spent within territories $(<1 \mathrm{~km}$ from nest location) by territorial birds. Data from
September and October 2016. The coefficient of variance (CV) refers to variation in time spent at each location

\begin{tabular}{|c|c|c|c|c|c|c|c|c|c|c|}
\hline & \multirow[b]{2}{*}{ Days } & \multicolumn{4}{|l|}{ September } & \multirow[b]{2}{*}{ days } & \multicolumn{4}{|l|}{ October } \\
\hline & & Hours \pm SD & $\%$ time & $\mathrm{CV}$ & Number & & Hours \pm SD & $\mathrm{CV}$ & \%time & Number \\
\hline \multicolumn{11}{|c|}{ Time at the mountain resting area } \\
\hline Territorial females & $13.8 \pm 11.1$ & $47: 29 \pm 55: 16$ & 12.8 & 1.17 & 8 & $13.4 \pm 6.3$ & $36: 14 \pm 17: 34$ & 0.49 & 10.2 & 7 \\
\hline Non-territorial females & $17.1 \pm 7.2$ & $79: 10 \pm 43: 20$ & 21.4 & 0.54 & 7 & $14.4 \pm 4.8$ & $49: 54 \pm 22: 15$ & 0.44 & 14.0 & 7 \\
\hline Territorial males & $22.0 \pm 4.7$ & $69: 40 \pm 37: 16$ & 18.9 & 0.54 & 4 & $10.8 \pm 7.9$ & $35: 44 \pm 35: 20$ & 0.99 & 10.1 & 5 \\
\hline Non-territorial males & $16.3 \pm 10.6$ & $52: 16 \pm 40: 50$ & 14.1 & 0.77 & 7 & $12.6 \pm 6.9$ & $40: 39 \pm 27: 21$ & 0.67 & 11.4 & 7 \\
\hline \multicolumn{11}{|l|}{ Time at the feeding station } \\
\hline Territorial females & $16.8 \pm 6.8$ & $61: 25 \pm 33: 59$ & 17.2 & 0.56 & 13 & $17.1 \pm 7.7$ & $57: 12 \pm 37: 51$ & 0.67 & 16.5 & 14 \\
\hline Non-territorial females & $15.8 \pm 5.8$ & $58: 42 \pm 23: 53$ & 15.9 & 0.40 & 8 & $15.9 \pm 9.5$ & $55: 08 \pm 42: 29$ & 0.77 & 15.5 & 9 \\
\hline Territorial males & $16.4 \pm 5.5$ & $38: 41 \pm 21: 44$ & 10.5 & 0.58 & 8 & $11.8 \pm 6.9$ & $28: 38 \pm 20: 19$ & 0.70 & 8.1 & 9 \\
\hline Non-territorial males & $14.8 \pm 8.5$ & $36: 23 \pm 27: 09$ & 9.9 & 0.75 & 9 & $14.7 \pm 5.4$ & $32: 46 \pm 17: 17$ & 0.53 & 9.2 & 7 \\
\hline \multicolumn{11}{|c|}{ Time spent within territories } \\
\hline Territorial females & $15.1 \pm 9.4$ & $44: 05 \pm 37: 38$ & 11.9 & 0.86 & 9 & $10.6 \pm 9.0$ & $21: 42 \pm 12: 07$ & 0.55 & 6.1 & 11 \\
\hline Territorial males & $19 \pm 12.2$ & $70: 57 \pm 57: 36$ & 19.2 & 0.81 & 9 & $19.5 \pm 9.6$ & $58: 09 \pm 47: 28$ & 0.82 & 16.4 & 8 \\
\hline
\end{tabular}

area. Vultures not visiting the resting area also did not spend much time at the feeding station $\left(\mathrm{F}_{1,72.8}=18.06, p<0.001\right.$, no effect of sex and/or territorial status). However, dominant males did not visit the mountain resting area $(\beta=-13.2 \pm$ 5.27 SE, $\mathrm{F}_{1,6}=6.25, p=0.0456$; Fig. 3).

\section{Allopreening behaviours}

Pairs visiting the feeding station often engage in mutual allopreening, most commonly involving preening of the neck and head feathers (Fig. 4a). However, we observed 17 cases of allopreening (involving at least one individually marked bird) outside a pair-living context (Feb $(2 \times)$, June $(2 \times)$, Aug $(5 \times)$,
Sep $(5 \times)$, Oct $(2 \times)$, Nov $(1 \times)$, summarized in Table S1). As opposed to allopreening between pair members, this behaviour was usually non-reciprocal (video 1 van Overveld 2019a). In half of these cases, allopreening behaviour occurred between young, unpaired birds (median age 4 years, range $2-7, n=7$ ), with both males and females acting as initiators or recipients (Table S1). One unpaired female was observed in allopreening with three different unpaired males within a 1.5 -year period (Fig. 4b; Fig. S7). In three cases, paired birds were preening other paired or unpaired birds (Table S1; Fig. 4c; Fig. S8). In another three cases, allopreening was observed among samesex birds (female-female (video 2 van Overveld 2019b), malemale (video 3 van Overveld 2019c)). We twice observed an
Table 3 Results of GLMM on seasonal effects and social status on time spent at the central feeding station (June 2016-May 2017), mountain resting area (September/October 2016) and time spent $<1 \mathrm{~km}$ from the nest location for territorial female $(n=12)$ and male $(n=9)$ Egyptian vultures tracked with GPS-loggers on Fuerteventura. Statistically significant associations $(p \leq 0.05)$ are denoted in italics

\begin{tabular}{|c|c|c|c|c|c|c|c|c|c|}
\hline \multirow[b]{2}{*}{ fixed effects } & \multicolumn{2}{|c|}{ Feeding station (June-May) } & \multicolumn{3}{|c|}{ Mountain resting area (Sep/Oct) } & \multicolumn{2}{|c|}{ Territory (June-May) } & \multirow[b]{2}{*}{$\mathrm{F}_{\text {NUMdf, DENdf }}$} & \multirow[b]{2}{*}{$p$} \\
\hline & $\beta(\mathrm{SE})$ & $\mathrm{F}_{\text {NUMdf, DENdf }}$ & $p$ & $\beta(\mathrm{SE})$ & $\mathrm{F}_{\text {NUMdf, DENdf }}$ & $p$ & $\beta(\mathrm{SE})$ & & \\
\hline \multicolumn{10}{|l|}{ Territorial females } \\
\hline Social rank & $4.20(1.71)$ & $6.06_{1,14.1}$ & 0.0273 & $0.95(2.17)$ & $0.19_{1,9.98}$ & 0.67 & $-2.38(5.27)$ & $0.00_{1,11.5}$ & 0.98 \\
\hline Month & $-0.25(0.11)$ & 5.131138 & 0.0250 & $0.25(0.28)$ & $0.80_{1,10.3}$ & 0.39 & $0.22(0.12)$ & 3.291128 & 0.07 \\
\hline Month $^{2}$ & $0.06(0.11)$ & 25.671138 & $<0.0001$ & $\mathrm{n} / \mathrm{a}$ & $\mathrm{n} / \mathrm{a}$ & $\mathrm{n} / \mathrm{a}$ & $-0.05(0.01)$ & 18.121128 & $<0.0001$ \\
\hline Month $^{2} *$ Rank & $-0.03(0.01)$ & 7.771138 & 0.0061 & $\mathrm{n} / \mathrm{a}$ & $\mathrm{n} / \mathrm{a}$ & $\mathrm{n} / \mathrm{a}$ & $0.04(0.01)$ & 8.671128 & 0.0038 \\
\hline \multicolumn{10}{|l|}{ Territorial males } \\
\hline Social rank & $0.40(2.79)$ & $0.02_{1,7.47}$ & 0.89 & $-13.2(5.27)$ & $6.25_{1,6}$ & 0.0465 & $-1.48(3.57)$ & $0.21_{1,6.71}$ & 0.66 \\
\hline Month & $0.10(0.11)$ & $0.89_{1,85}$ & 0.35 & $0.38(0.19)$ & $3.94_{1,7}$ & 0.0876 & $0.31(0.15)$ & $4.58_{1,85}$ & 0.0353 \\
\hline Month $^{2}$ & $0.03(0.01)$ & $8.84_{1,85}$ & 0.0038 & $\mathrm{n} / \mathrm{a}$ & $\mathrm{n} / \mathrm{a}$ & $\mathrm{n} / \mathrm{a}$ & $-0.05(0.01)$ & $15.64_{1,85}$ & 0.0002 \\
\hline Month $^{2} *$ Rank & $-0.07(0.02)$ & $16.89_{1,85}$ & $<0.0001$ & $\mathrm{n} / \mathrm{a}$ & $\mathrm{n} / \mathrm{a}$ & $\mathrm{n} / \mathrm{a}$ & $0.06(0.02)$ & $6.79_{1,85}$ & 0.0108 \\
\hline
\end{tabular}


Fig. 4 Allopreening birds at the central feeding station on Fuerteventura showing a members of a pair from Lanzarote, $\mathbf{b}$ an unpaired male preening an unpaired female (note that a previously preened female by the same male is sitting next to him), $\mathbf{c}$ a paired female preening a male of a different pair and $\mathbf{d}$ an adult bird preening a 2-year old male. Photos: T. van Overveld
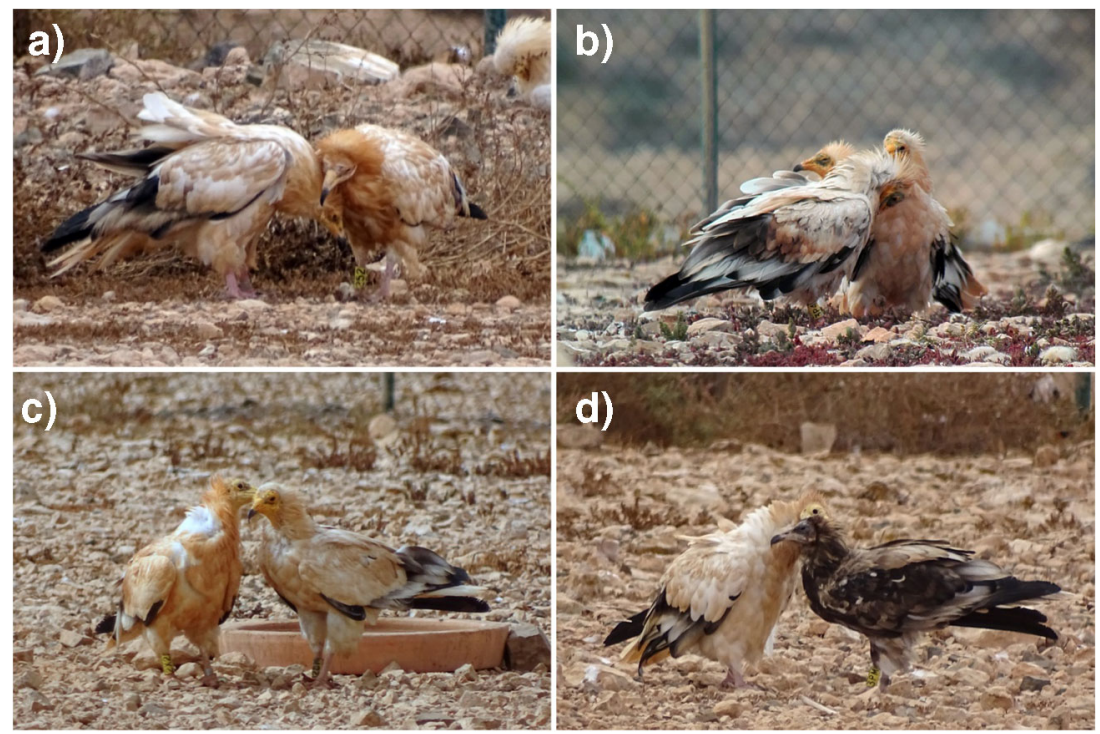

adult bird preening immature birds (Fig. 4d). Note that Canarian Egyptian vultures do not provide post-fledging care (LG, unpublished data). In none of the cases, allopreening involved family members as based on pedigree data.

\section{Discussion}

Despite the widespread occurrence of seasonal sociality among animals, detailed information about the ecological and social mechanisms driving seasonal variation in social dynamics is still scarce, especially for avian social systems (Silk et al. 2014; but see Uhl et al. 2018). Our study provides novel insights on how seasonal grouping patterns result from the complex interplay between ecological and individualbased social factors and highlights the need of combining different sources of data (i.e. modern GPS-tracking and basic behavioural observations) to understand this complex phenomenon.

As predicted, group sizes at the central feeding station followed a strong seasonal pattern characterized by distinct monthly changes in group composition. The number of adult breeders visiting this feeding patch was typically low at the start of the breeding season, but their numbers gradually increased from the egg-laying phase onwards, most probably as a result of nest failure and fledging of young (only $40 \%$ of breeders raise young, unpublished data see also García-Heras et al. 2013; van Overveld et al. 2018). The low number of unpaired/non-territorial birds observed during the breeding season confirms results obtained from GPS-tracking, showing that these birds, and males in particular, make large-scale explorative flights in this period, often covering the entire island of Fuerteventura (van Overveld et al. 2018; see also Fig. S6). Since unpaired birds were largely absent throughout the entire breeding season, this seems to suggest that they may not only search for vacant territories, but also gather information about the quality of existing territories and their owners (Valone and Templeton 2002). Lastly, as predicted, a relatively large proportion of immature birds was present at the feeding station throughout the year, which at least in part could be linked to their poor foraging skills and limited environmental knowledge, as shown in many other bird species (e.g. Sanz-Aguilar et al. 2015). Similar factors may also explain why nearly all newly fledged birds within the population can be found at this site.

While reproductive activities, information gathering and age-specific foraging constraints may importantly explain seasonal variation in group size and composition, it is striking that vultures show such a clear preference for the centrally located feeding station. In between reproductive periods, vulture numbers at this feeding patch (and a nearby temporary roosting site) may reach up to $30-50 \%$ of the total population on a single day consisting of ca. $80 \%$ of the total population of each individual category. During this period, unpaired and paired vultures, depending on social status, may spend on average $30 \%$ of their monthly time in a social gathering context. These gatherings are particularly remarkable since vultures largely neglect a feeding station that is located at only $40 \mathrm{~km}$ distance from this site (see also van Overveld et al. 2018), while both adults and fledglings from the nearby island of Lanzarote prefer to spend their summer in the centre of Fuerteventura, even though a feeding station is also present on the former island (Fig. 1). Furthermore, although the mountain resting area may be linked to the use of the central feeding station, i.e. this roost provides an overview of the plain where the central feeding site is located, this site is typically not used year-round, and visited by both local and nonlocal breeders (and unpaired birds), although not by highranked territorial males.

The general preference for the central feeding station, and the formation of a temporary roost nearby, seems importantly 
linked to its location near traditional breeding grounds (Donázar et al. 2002b). Although the population has steadily increased and expanded over the past 20 years (Badia-Boher et al. 2019), the highest density of breeding pairs can still be found within this area. This feeding station was the first established at the start of the study period in 1999, suggesting that apart from its specific geographic location, historical factors and habituation effects potentially also play a role (e.g. 'socially inherited routines', Valenzuela et al. 2009; Andrew 2017), especially when taking into consideration that almost all individuals within the population have been feeding at this site from an early age.

The increase in vulture numbers at the feeding station also seems to reflect an overall shift in foraging activities towards the centre of Fuerteventura (Fig. 1). It is possible that vultures partly abandon their territories because of a seasonal reduction in the availability of natural carrion resources (Medina 1999). By gathering in the centre, vultures may reduce searching time for natural available goat carcasses and those provided at farms (i.e. through 'local enhancement' effects Cortés-Avizanda et al. 2014), while taking advantage of food dumps at the central feeding station. On the other hand, however, the high density of vultures in the centre may increase the cost of food exploitation, in particular for individuals from remote areas which are typically lower ranked (van Overveld et al. 2018). Since there are many goat farms distributed throughout the island and given the semi-predictable character of this resource type, the social foraging benefits for lower-ranked birds are currently not fully understood. In addition, if food availability would truly be limited in summer (e.g. driving social foraging tactics), we would also expect that other feeding stations would be used more frequently, which is not the case.

As a last explanation, we propose that this feeding patch may also be visited for social purposes. Besides foraging, Egyptian vultures display a wide variety of activities at this site, most notably conflict-settlement (between neighbouring territorial or between unpaired birds), allopreening (among and between paired and unpaired birds, see below) and extensive copulation activities (in the pre-breeding period). Social gatherings may be of particular relevance for territorial vultures that are facultative social foragers, which social structures are characterized by strong age- and sex-dependent hierarchical relationships, with social rank also being linked to territorial status (van Overveld et al. 2018; this study). Within such highly despotic societies, rank maintenance and improvement may form an integral part of the daily activities, beginning as soon as young fledge (Fig. S9). Group foraging events, where many other individuals can be found in a competitive context, may attract special attention, given opportunities to strengthen/improve social rank, to gain knowledge about the social rank of conspecifics and potentially also to update information about their own relative fighting ability/ social status within the population (Rutte et al. 2006). Apart from food exploitation, feeding sites may importantly contribute in optimizing decision-making about future interactions (e.g. to avoid costly conflicts) and potential mates.

Although we acknowledge the inherent difficulty in assessing whether individuals actively join gatherings for social purposes, extensive behavioural observations on agonistic and affiliative interactions nevertheless point towards the existence of well-developed social communication skills in this species. Despite the complex fission-fusion dynamics characterizing their group feeding, with individuals coming and going at different times and rates during the day (or so called 'open groups': Boucherie et al. 2019; see also introduction), Egyptian vultures rarely fight extensively over food and competitive displacements are often subtle. Competitive interactions and aggression levels may be regulated by body-size differences, but probably also through information on age and social rank (e.g. Paz-y-Miño et al. 2004; Massen et al. 2014). During feeding, individuals often first look around and specifically select a lower-ranked bird of the same sex and age to be displaced, which suggests the existence of an active avoidance/attack strategy based on individual recognition. Furthermore, escalated fights, although rare, typically attract much attention and are carefully watched by bystanders (Fig. 5; video 4 Mulet 2019). Social conflicts may also be settled through ritualized dominance displays (e.g. 'duels', whereby birds erect their head and neck feathers, and 'parade' face to face, until one or both birds attacks, or retreats (video 5 van Overveld 2019d). Although threat displays are common in birds (Hurd and Enquist 2001), we are currently not aware of other (non-vulture) bird species that evolved such a distinct and elaborate agonistic repertoire.

Apart from antagonistic displays, vultures also frequently engage in affiliative interactions through non-reciprocal allopreening outside a pair-living context. We speculate that this behaviour may primarily serve a function in mate-seeking

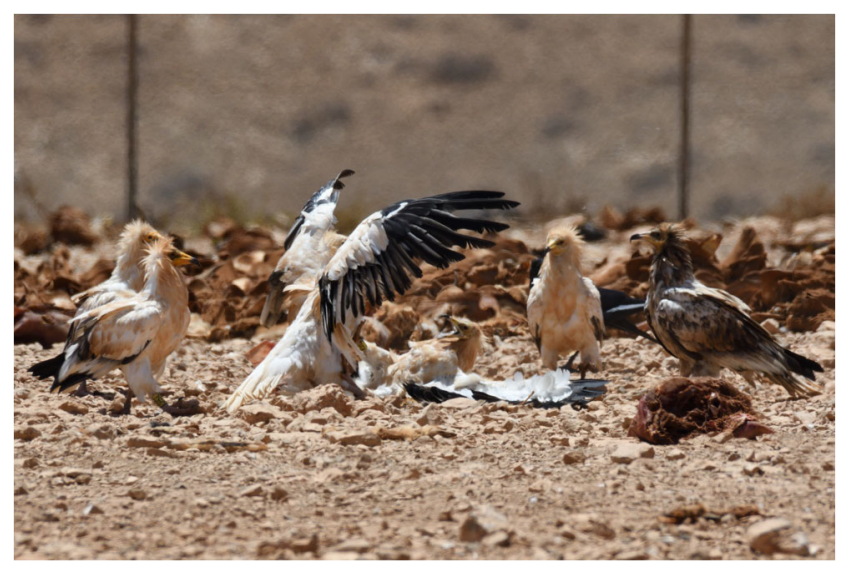

Fig. 5 Example of an escalated fight between two females outside the breeding season (August). Note that these fights are carefully watched by other birds. On some occasions, these bystanders may start to peck on the defeated individual. Photo: T. van Overveld 
or mate-sampling, since the behaviour is displayed mostly by unpaired birds at the age of recruitment (e.g. 3-7 years). Allopreening among paired and (un)paired birds may be linked to their complex mating strategies, with the frequent occurrence of both polyandrous and polygynous trios on Fuerteventura (authors unpublished). However, occasional observations of the behaviour in more complex social setting, such as among same-sex birds and unrelated adults and immatures, may point towards alternative social functions such as stress reduction and/or conflict avoidance (Rabenold 1986; Bertran and Margalida 2003; Radford and du PLessis 2006; Lewis et al. 2007). An intriguing question is whether these specific interactions reflect the existence of secondary relationships (Boucherie et al. 2019) and/or specific postconflict repair for social bonding purposes (Fraser and Bugnyar 2011). Although Egyptian vultures do not form distinct social alliances during foraging as observed in some social corvids (Fraser and Bugnyar 2012), it is possible that hierarchical social relations include more complex sublayers linked to specific individual strategies for rank acquisition.

To conclude, our findings show that seasonal grouping patterns are shaped by the complex interplay between ecological factors (reproductive constraints, resource seasonality and food predictability), individual traits (age, sex and rank within hierarchy) and social competitive processes. We argue that vultures visit large gatherings at food resources also for social purposes. Group foraging events may be of special interest to vultures given opportunities for rank improvement/maintenance, but potentially also for mate-seeking/evaluation, and in general act as important places where young birds become integrated within local population social structures. An important, but challenging, goal for future work will be to determine whether (or which) individuals actively join social gatherings for social purposes and the potential gains in fitness to fully assess its potential role as a 'meeting place'. In addition, future studies should also reveal whether social gatherings fulfil a similar role in mainland populations and/or to what extent sedentary island conditions promote the formation of more complex social relations and/or stronger dominance hierarchies. Lastly, we provided examples of the agonistic and affiliative repertoire of Egyptian vultures, further adding to other unique behaviours displayed by the species such as stone throwing to open eggs (van Lawick-Goodall and van Lawick 1966; Carrete et al. 2017), mud-bathing (van Overveld et al. 2017) and coprophagy (Negro et al. 2002). We propose that vultures, like corvids, may serve as important model species to test the role of scavenging and fission-fusion social dynamics in shaping the evolution of avian social cognition, or avian behavioural complexity generally. Overall, our work highlights the need for more in-depth knowledge about the rich social life of vultures, which could be invaluable for understanding vulture social responses to current environmental changes.
Acknowledgments We thank Ana Trujillano, Carmen Díez, Marcos Mallo, Walo Moreno, Toni Mulet, Juan Ramírez and Julio Roldán for their invaluable work in monitoring the "Guirre" population on the Canary Islands. We thank two anonymous reviewers for their helpful comments to improve and clarify this manuscript.

Author contributions All the authors were involved in conducting fieldwork. TvO conceptualized research questions. TvO collected behavioural data on agonistic and affiliative interactions. TvO carried out the statistical analyses with input from $\mathrm{LG}$. TvO wrote the manuscript with editorial input from all co-authors (LG, MG-A, WB, MdIR, JD). All the authors gave final approval for publication.

Funding information TvO received funding from the European Union's Horizon 2020 research and innovation programme under the Marie Sklodowska-Curie grant agreement no. "SocForVul 659008." During writing, LG was supported by a Marie Sklodowska-Curie Fellowship of the European Commission (grant number: 747729 "EcoEvoClim"). MGA was supported by a contract from "Programa de FPU del Ministerio de Educación, Cultura y Deporte" (FPU13/05429). The long-term monitoring of the vulture population has been funded by the projects REN 2000 1556 GLO, CGL2004-00270/BOS, CGL2009-12753-C02-02, CGL2012-40013-C02-01 and CGL2015-66966-C2-1-2-R (Spanish Ministry of Economy and Competitiveness and EU/FEDER). Further support was provided by the Cabildo Insular de Fuerteventura and the Dirección General de Protección de la Naturaleza (Viceconsejería de Medio Ambiente, Canarian Government).

\section{Compliance with ethical standards}

Conflict of interest The authors declare no competing interests.

Ethical approval All applicable international, national and/or institutional guidelines for the care and use of animals were followed. All procedures performed in studies involving animals were in accordance with the ethical standards of the institution or practice at which the studies were conducted (Ethic Committee of CSIC (CEBA-EBD-12-56).

\section{References}

Andrew A (2017) A second inheritance system: the extension of biology through culture. Interface Focus 7:20160142. https://doi.org/10. 1098/rsfs.2016.0142

Aureli F, Schaffner CM, Boesch C et al (2008) Fission-fusion dynamics: new research frameworks. Curr Anthropol 49:627-654

Badia-Boher J, Sanz-Aguilar A, de la Riva M, Gangoso L, van Overveld T, García-Alfonso M, Luzardo O, Suarez-Pérez A, Donazar JA (2019) Evaluating European LIFE conservation projects: improvements in survival of an endangered vulture. J Appl Ecol 56:1210 1219

Bertran J, Margalida A (2003) Male-male mountings in polyandrous bearded vultures Gypaetus barbatus: an unusual behaviour in raptors. J Avian Biol 34:334-338

Boucherie PH, Loretto MC, Massen JJM, Bugnyar T (2019) What constitutes "social complexity" and "social intelligence" in birds? Lessons from ravens. Behav Ecol Sociobiol 73:12. https://doi.org/ 10.1007/s00265-018-2607-2

Boucherie PH, Mariette MM, Bret C, Dufour V (2016) Bonding beyond the pair in a monogamous bird: impact on social structure in adult rooks (Corvus frugilegus). Behaviour 153:897-925 
Buckley NJ (1997) Experimental tests of the information-center hypothesis with black vultures (Coragyps atratus) and Turkey vultures (Cathartes aura). Behav Ecol Sociobiol 41:267-279

Buechley ER, Sekercioglua CH (2016) The avian scavenger crisis: looming extinctions, trophic cascades, and loss of critical ecosystem functions. Biol Conserv 198:220-228

Campbell MO (2015) Vultures: their evolution. CRC Press, Boca Raton, FL, Ecology and Conservation

Carrete M, Centeno-Cuadros A, Méndez M, Agudo R, Donázar JA (2017) Low heritability in tool use skills in a wild vulture population. Anim Behav 129:127-131

Cortés-Avizanda A, Jovani R, Donázar JA, Grimm V (2014) Bird sky networks: how do avian scavengers use social information to find carrion? Ecology 95:1799-1808

Curley JP (2016) Compete: analyzing social hierarchies: R package version 0.1 , https://github.com/jalapic/compete

Dall SRX, Wright J (2009) Rich pickings near large communal roosts favor 'gang' foraging by juvenile common ravens, Corvus corax. PLoS One 4:e4530

Dermody BJ, Tanner CJ, Jackson AL (2011) The evolutionary pathway to obligate scavenging in Gyps vultures. PLoS One 6:e24635

Donázar JA, Negro JJ, Palacios CJ, Godoy JA, Ceballos O, Hiraldo F, Capote N (2002a) Description of a new subspecies of the Egyptian vulture (Accipitridae: Neophron percnopterus) from the Canary Islands. J Raptor Res 36:17-23

Donázar JA, Palacios CJ, Gangoso L, Ceballos O, González MJ, Hiraldo $\mathrm{F}$ (2002b) Conservation status and limiting factors in the endangered population of Egyptian vulture (Neophron percnopterus) in the Canary Islands. Biol Conserv 107:89-97

Emery NJ, Clayton NS (2004) The mentality of crows: convergent evolution of intelligence in corvids and apes. Science 306:1903-1907

Emery NJ, Seed AM, von Bayern AMP, Clayton NS (2007) Cognitive adaptations of social bonding in birds. Phil Trans R Soc B 362:489 505

Fishlock V, Lee PC (2013) Forest elephants: fission-fusion and social arenas. Anim Behav 85:357-363

Fraser ON, Bugnyar T (2011) Ravens reconcile after aggressive conflicts with valuable partners. PLoS One 6:e18118

Fraser ON, Bugnyar T (2012) Reciprocity of agonistic support in ravens. Anim Behav 83:171-177

Gammell MP, de Vries H, Jennings DJ, Carlin CM, Hayden TJ (2003) David's score: a more appropriate dominance ranking method than Clutton-Brock et al.'s index. Anim Behav 66:601-605

García-Heras M, Cortés-Avizanda A, Donázar JA (2013) Who are we feeding? Asymmetric individual use of surplus food resources in an insular population of the endangered Egyptian vulture Neophron percnopterus. PLoS One 8:e80523

Harel R, Spiegel O, Getz WM, Nathan R (2017) Social foraging and individual consistency in following behaviour: testing the information centre hypothesis in free-ranging vultures. Proc R Soc B 284: 20162654

Hurd PL, Enquist M (2001) Threat display in birds. Can J Zool 79:931942

Kappeler PM (2019) A framework for studying social complexity. Behav Ecol Sociobiol 73:13-14. https://doi.org/10.1007/s00265-0182601-8

Kappeler PM, Clutton-Brock T, Shultz S, Lukas D (2019) Social complexity: patterns, processes, and evolution. Behav Ecol Sociobiol 73:5-6. https://doi.org/10.1007/s00265-018-2613-4

Krause J, Ruxton GD (2002) Living in groups. Oxford University Press, Oxford

Lewis S, Roberts G, Harris MP, Prigmore C, Wanless S (2007) Fitness increases with partner and neighbour allopreening. Biol Lett 3:386389
Loretto MC, Schuster R, Itty C, Marchand P, Genero F, Bugnyar T (2017) Fission-fusion dynamics over large distances in raven non-breeders. Sci Rep 7:380

Marzluff JM, Heinrich B (1991) Foraging by common ravens in the presence and absence of territory holders: an experimental analysis of social foraging. Anim Behav 42:755-770

Massen JJ (2018) Friendships in animals. In: Vonk J, Shackelford T (eds) Encyclopedia of animal cognition and behavior. Springer, Cham

Massen JJM, Pašukonis A, Schmidt J, Bugnyar T (2014) Ravens notice dominance reversals among conspecifics within and outside their social group. Nat Commun 5:3679

Medina FM (1999) Alimentación del alimoche, Neophron percnopterus (L.), en Fuerteventura, islas Canarias (Aves, Accipitridae). Vieraea 27:77-86

Møller AP, Laursen K (2019) The ecological significance of extremely large flocks of birds. Ecol Evol 9:6559-6567

Mulet T (2019) Video 5: escalated fight between female Egyptian vultures, https://figshare.com/s/d27573c03393e1f1c0d2

Negro JJ, Grande JM, Tella JL, Garrido J, Hornero D, Donázar JA, Sanchez-Zapata JA, Benítez JR, Barcell M (2002) An unusual source of essential carotenoids. Nature 416:807-808

Ogada D, Keesing F, Virani MZ (2012) Dropping dead: causes and consequences of vulture population declines worldwide. Ann N Y Acad Sci 1249:57-71

Paz-y-Miño CG, Bond AB, Kamil AC, Balda RP (2004) Pinyon jays use transitive inference to predict social dominance. Nature 430:778781

Porter RF, Suleiman AS (2012) The Egyptian vulture Neophron percnopterus on Socotra, Yemen: population, ecology, conservation and ethno-ornithology. Sandgrouse 34:44-62

Rabenold PP (1986) Family associations in communally roosting black vultures. Auk 103:32-41

Radford AN, du Plessis MA (2006) Dual function of allopreening in the cooperatively breeding green woodhoopoe, Phoeniculus purpureus. Behav Ecol Sociobiol 61:221-230

Ramos-Fernandez G, King AJ, Beehner JC et al (2018) Quantifying uncertainty due to fission-fusion dynamics as a component of social complexity. Proc R Soc B 285:20180532

R Core Team (2017) R: A language and environment for statistical computing. R Foundation for Statistical Computing, Vienna, Austria. http://www.R-project.org/. Accessed 22 Jan 2020

Richner H (1989) Phenotypic correlates of dominance in carrion crows and their effects on access to food. Anim Behav 38:606-612

Rutte C, Taborsky M, Brinkhof MWG (2006) What sets the odds of winning and losing? Trends Ecol Evol 21:16-21

Sanz-Aguilar A, Jovani R, Melian C, Pradel R, Tella JL (2015) Multievent capture-recapture analysis reveals individual foraging specialization in a generalist species. Ecology 96:1650-1660

Sergio F, Tavecchia G, Tanferna A, López Jiménez L, Blas J, De Stephanis R, Marchant TA, Kumar N, Hiraldo F (2015) No effect of satellite tagging on survival, recruitment, longevity, productivity and social dominance of a raptor, and the provisioning and condition of its offspring. J Appl Ecol 52:1665-1675

Silk MJ, Croft DP, Tregenza T, Bearhop S (2014) The importance of fission - fusion social group dynamics in birds. Ibis 156:701-715

Smith-Aguilar SE, Ramos-Fernández G, Getz WM (2016) Seasonal changes in socio-spatial structure in a group of free-living spider monkeys (Ateles geoffroyi). PLoS One 11:e0157228

Sueur C, King AJ, Conradt L, Kerth G, Lusseau D, Mettke-Hofmann C, Schaffner CM, Williams L, Zinner D, Aureli F (2011) Collective decision-making and fission-fusion dynamics: a conceptual framework. Oikos 20:1608-1617

Uhl F, Ringler M, Miller R, Deventer SA, Bugnyar T, Schwab C (2018) Counting crows: population structure and group size variation in an urban population of crows. Behav Ecol 30:57-67 
Valenzuela LO, Sironi M, Rowntree VJ, Seger J (2009) Isotopic and genetic evidence for culturally inherited site fidelity to feeding grounds in southern right whales (Eubalena australis). Mol Ecol 18:782-791

Valone TJ, Templeton JJ (2002) Public information for the assessment of quality: a widespread social phenomenon. Phil Trans R Soc B 357: $1549-1557$

van Lawick-Goodall J, van Lawick H (1966) Use of tools by Egyptian vultures Neophron percnopterus. Nature 212:1468-1469

van Overveld T (2019a) Video 1: Egyptian vultures allopreening between unpaired male and female. https://figshare.com/s/ 38aad91fcab3515faa97

van Overveld T (2019b) Video 2: Egyptian vultures same-sex preening (females). https://figshare.com/s/f040b6bf7e2f4fe01324 van Overveld T (2019c) Video 3: Egyptian vultures same-sex preening (males). https://figshare.com/s/6127f969703974d0bb11

van Overveld T (2019d) Video 4: Egyptian vultures ritualized dominance display. https://figshare.com/s/099a3be5d261522ef1 8d

van Overveld T, de la Riva M, Donázar JA (2017) Cosmetic coloration in Egyptian vultures: mud bathing as a tool for social communication? Ecology 98:2216-2218

van Overveld T, García-Alfonso M, Dingemanse NJ, Bouten W, Gangoso L, de la Riva M, Serrano D, Donázar JA (2018) Food predictability and social status drive individual resource specializations in a territorial vulture. Sci Rep 8:15155

Publisher's note Springer Nature remains neutral with regard to jurisdictional claims in published maps and institutional affiliations. 